\title{
Elementary Introduction on Redesign and Reutilization of Remainder of Mahogany Furniture
}

\author{
Hengwang Zhang \\ Shandong University of Arts \\ Shandong, China \\ Email: 403676956@qq.com
}

\begin{abstract}
Mahogany furniture has excellent characteristics in material, appearance, technology and aesthetic value, etc. In recent years, the revival of traditional cultural has brought more and more market demand of China's traditional mahogany furniture. However, the benefits brought by the huge demand of the mahogany furniture market lead to no more energy used in furniture design and material reutilization in the production of products, resulting in the waste of scarce material resources. By analyzing the production status of mahogany furniture enterprises and the status of remainder of mahogany materials, this paper combs the processing methods of remainder in mahogany furniture enterprises. From the point of view of design, this paper discusses how to redesign and reutilize the remainder in mahogany furniture enterprises, and with specific design practice as a guide, to really make use of the design into life, to realize the recycling of remainder in mahogany furniture enterprises, and guide the mahogany furniture enterprises to implement green design scheme.
\end{abstract}

\section{Keywords: Mahogany, Remainder, Reutilization}

\section{INTRODUCTION}

Mahogany is a kind of material that continues the life of plants. After more than 100 years of natural baptism, it has formed unique texture, color and smell. The furniture made with mahogany is hard and dense. The color is elegant and the texture is lively and magnificent. It gives people a sense of solemnity and warmth, which cannot be replaced by any other material. Mahogany tree has the characteristics of slow growth, low output and large market demand, which leads to the growing lack and high price of mahogany raw materials on the market, and some valuable mahogany even means 'material is gold'.

The revival of traditional culture has expanded the demand of mahogany furniture, and the mahogany furniture enterprises have grown steadily in the furniture industry. Under the heavy prize, there must be brave men. In the same way, the rich benefits drive more mahogany furniture enterprises to expand.
In the repaid circulation of production, the waste of resources is negligible.

At present, most of mahogany furniture enterprises have problems of 'remainder' waste. The so-called 'remainder' refers to the residual material and leftover material in the process of production and manufacture of the mahogany furniture enterprises, because of natural factors or other human factors, they are not fully used during the process of processing, and cannot continue to be processed for the parts of the product, namely, they are what we usually call 'leftover pieces' and 'scrap'.

According to the current survey, in ordinary furniture enterprises, only about $2 / 3$ remainder can be reprocessed \& reutilized and 1/3 remainder can only be used as firewood. The value of 'remainder' produced by mahogany furniture enterprises is far greater than the value of ordinary remainder. According to the survey, the manufacturers generally use the way of centralized stacking in the early stage of utilization of remainder, and simply stack into the corner, with few effective measures. Based on this, if we can plan a good solution, there is no doubt that it will save the cost, improve the profit, and also contribute to the green and sustainable development. So in the background of building an environment friendly society, it is particularly important on how to make rational use of mahogany remainder. The reutilization and redesign of mahogany remainder have also become the urgent problems for current mahogany furniture enterprises.

\section{STATUS AND ANALYSIS OF THE UTILIZATION OF MAHOGANY REMAINDER}

According to the survey, at present, the furniture enterprises adopt the following measures for mahogany remainder:

\section{A. Sell off}

Usually, the enterprises first consider selling the remainder. The remainder with good color and 
quality shall be sold to handicraft factory first, to make small items such as decorative items and articles for amusement, etc. Smaller pieces of wood and sawdust shall be sold to sawdust processing plant for water control and metallurgical industry, or for producing activated carbon. This method can not only quickly solve the problem of waste accumulation in the workshop, but also transform them into money, which seems to be a win-win situation. However, there are many disadvantages: (1) It consumes a lot of human resources and increases the cost of production. (2) The selling price of mahogany remainder is extremely cheap, and the economic cost of the enterprise is improved (for example, Siam Rosewood is more than 300 Thousand Yuan a ton, but the purchase price of remainder is only a few hundred Yuan). (3) The remainder sold to the sawdust plant is generally disposed by the way of burning, which reduces the value of the valuable timber (for example, some mahogany even can be as the medicine). Today, more and more attention is paid to the ecological environment. Low-level and extensive energy absorption methods have resulted in almost no living space for enterprises to obtain heat from wood combustion.

\section{B. Burn off}

Every furniture enterprise needs the different amount of heat energy demand, and mahogany furniture enterprise is no exception. Because of the influence of traditional concept of obtaining heat from wood combustion, and considering the selling disadvantages of taking a long time and a lot of work, many enterprises burn the remainder directly to obtain the heat energy needed for production and life. Burning is simple and direct, can quickly dispose the remainder, however, it causes pollution to the air environment, and is very easy to cause fire, to bring devastating disaster to the enterprise. This way cannot reflect the concept of environment-friendly ecology, and the enterprises are trying to transform the processing methods under the background of environment protection.

\section{Reutilization}

The redesign and reutilization of remainder can not only save costs, but also bring additional value to enterprises, at the same time, can improve the utilization rate of the material and protect the environment. In reality, some enterprises are also starting to explore the reutilization method of mahogany remainder, and use it to make suitable products, but a large part of it is only as a general decoration and the practical value is not high. These products have unified characteristics: they belong to fewer categories of consumption, and they are the consumption contents that can only be produced after people have satisfied their basic life. It is very little that the remainder is really applied to furniture and the products meet the needs of most people. Even if there is, it is also rare, the overall level is not enough and the effect is poor.

\section{MARKET POSITIONING ANALYSIS OF MAHOGANY REMAINDER}

\section{A. Market Demand Analysis}

The raw materials of mahogany remainder are all precious wood, so the remainder is basically the leftover material after maximum utilization of materials of manufacturers. This means that mahogany remainder is less than that of ordinary sold wood furniture, which determines that the direction of our product design and development is small items.

In daily life, small items are the most complicated products used by people. The key is how to choose the angle to find the entry point. What is closely related to people's life includes eating, clothing, housing, consumption and transportation. In terms of eating, it includes cookers, bowls, ladles, basins and other cooking utensils and tableware; in terms of clothing, it includes wardrobes, shoe lockers, hangers and other furniture; in terms of housing, it includes houses and related facilities; in terms of consumption, it includes toothbrushes and dining-table, etc,; in term of transportation, it mainly includes vehicle, namely, cars, bicycles, electric cars and buses, etc. We can say that the daily necessities of our life almost cover all the products, that is to say, the market is very large.

\section{B. Development and Characteristics}

We can know from market demand analysis that people's daily life is full of the products used, and in the process of our use, our body often contacts with the goods, the most part of the contact is hands and the handles of various items. The parts of contact are also the most easily worn parts, which require design $\&$ development personnel to make better preparations for it.

\section{Existing Products on the Market}

The common handle materials in the market are relatively single, mainly two kinds of metal and plastic. The mahogany handle can solve the problem of wood remainder utilization. Moreover, the wood has mild color and good touch, which can avoid the 
cold feeling of metallic materials to people, and the cheap feeling of plastic materials. In addition, after contacting with the human body for a long time, through the chemical reaction and oxidation of the human skin secreted material, the surface of mahogany will form a layer of oxide film, which is 'patina'. Patina is gradually accumulated in the process of using the material, which just avoids the wear of metal or plastic materials after long time use, and the beautiful appearance of the patina will become more beautiful with time. The nature of mahogany 'beautiful patina' has also been highly praised in the amusement world.

\section{HANDLE DESIGN OF MAHOGANY REMAINDER}

The different types of mahogany remainder can determine the different styles of the product. We should design the product with the main principle of 'material application' and 'taking advantage of the situation', so as to give play to the characteristics of remainder and make a unique product. The specifications of mahogany remainder determine that the product to be developed has a small and delicate feature, and all the things used by people in life can be in contact with one part of the body or body in varying degrees. Among them, the hand is the most frequent contact with other objects in various organs of the human body. According to the specifications of mahogany remainder and the visual and tactile characteristics of the material, several different design methods are drawn from the angle of the handle.

\section{A. Long Strip Remainder}

In the process of production, most of the remainders are long strips. According to this characteristic, the handle can be designed with this shape. This method is easy in processing, but it is simple and elegant, and can display the texture of mahogany remainder very well, the visual effect is good (Figure. 1).

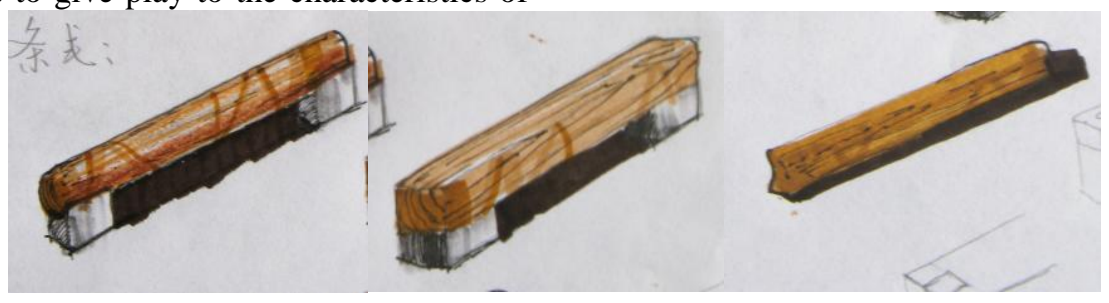

Figure 1 Strip effect

\section{B. Block Remainder}

The block remainder is also very common after processing. Block remainder has the uniqueness of smaller and square, so we can make use of the block shape to develop it in the direction of personality and make a very successful product after a little processing (Figure 2).

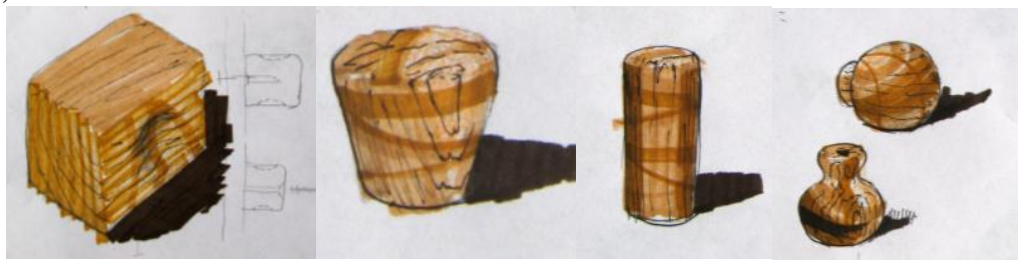

Figure 2 Block effect

\section{Learn from others' Strong Points and Close the Gap}

The defect of a material is often made up by another material, and this characteristic is obvious particularly in mahogany furniture remainder. Mahogany remainder itself often has some defects, such as scars, damaged by worms and fission, etc, which more or less missing the integrity of the wood to the human, and the collocation of different materials will produce different aesthetic feeling. For example Figure 3, the collocation between mahogany remainder and metal material, it is the collocation between warm and cold, between ancient and modern, the contrast will form a beautiful mood. 


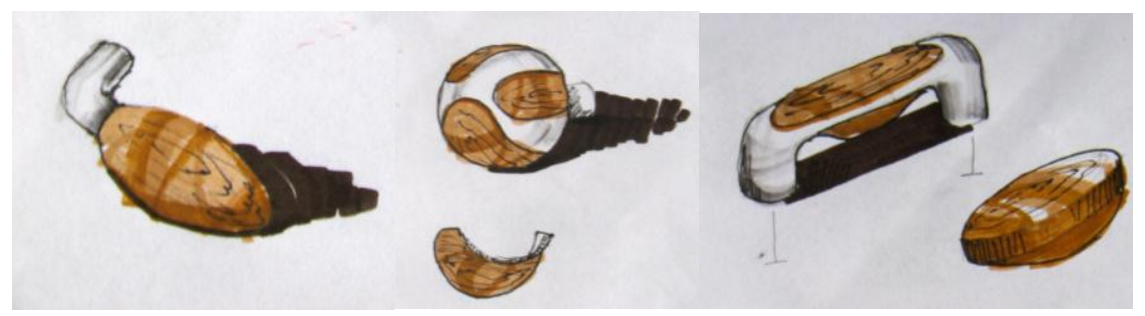

Figure 3 Other shape effects

\section{V.CONCLUSION}

The redesign and reprocessing of remainder in mahogany furniture enterprises can be described as having broad prospects and mainly located in small necessities that are suitable for the public. This paper takes the door handle as an example to specifically analyze how to make use of mahogany remainder skillfully, and draws the conclusion as follows: the redesign and reutilization of mahogany remainder should consider that different material, color, texture and shape shall express different design concepts. In the specific design, we should fully grasp the characteristics of different remainders, to express the best sense of design. The reprocessing and reutilization of mahogany remainder also show that in the future, our design shall not only have excellent appearance design and good use function, but also take into consideration the green environmental protection design at any time, and bear the responsibility of protecting the environment.

\section{REFERENCES}

[1] Weng Mingxia. Design Research on Reutilization of Wood Remainder in Furniture Enterprises [D]. Nanjing Forestry University, 2010. (In Chinese)

[2] Duan Feng, Fang Chongrong, Yu Haixia. Discussion on Production Status and Development of Mahogany Furniture and 'Mahogany' [J]. Journal of Zhejiang Forestry Science and Technology, 2011. (In Chinese)

[3] Gu Ping. Traditional Mahogany Culture \& Art and Modern Interior Design [D]. Nanjing Forestry University, 2005. (In Chinese) 